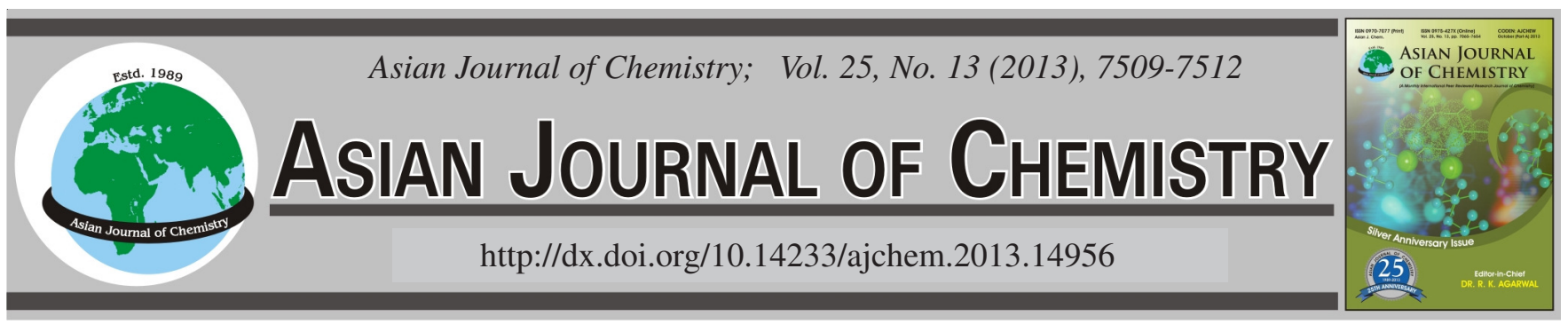

\title{
Poly(vinyl alcohol): An Economical Substitute to Calcium Lignosulphonate for PVC/PET Separation by Froth Flotation
}

\author{
Amir Shafeeq ${ }^{1}$, Rabya Aslam ${ }^{1}$, Shaukat Ali Shahid ${ }^{2, *}$, Ayyaz Muhammad ${ }^{1}$, Aamir Ijaz ${ }^{1}$,
} Arshid Mehmood Ali ${ }^{1}$, Inam Ullah ${ }^{3}$, Muhammad Mushtaq ${ }^{3}$ and Umer Rashid ${ }^{4, *}$

\begin{abstract}
${ }^{1}$ Institute of Chemical Engineering \& Technology, University of The Punjab, Lahore-54590, Pakistan
${ }^{2}$ Department of Physics, University of Agriculture Faisalabad-38040, Pakistan

${ }^{3}$ Department of Chemistry \& Biochemistry, University of Agriculture, Faisalabad-38040, Pakistan

${ }^{4}$ Institute of Advanced Technology, University Putra Malaysia, 43400 UPM Serdang, Selangor, Malaysia
\end{abstract}

*Corresponding authors: Fax: +92 41 9200109; Tel: +92 419200161 (ext. 3314); E-mail: shaukat.uafpy @ yahoo.com (Shaukat Ali Shahid) Fax: +60 389467006; Tel: +60 389467393; E-mail: umer.rashid@yahoo.com (Umer Rashid)

\begin{abstract}
The environmental and economic concerns have lead to the development of a number of management techniques to handle the waste polymers. Although recycling is considered as one of the most feasible solution to cater the plastic waste yet it is not implemented widely due to high cost involved in the process. Polyethylene terephthalate (PET) is one of the most recycled polymer, however, its separation from other polymers is necessary step prior to the recycling process. The separation of PVC/PET mixture by froth flotation technique using poly(vinyl alcohol) as an economical substitute of calcium lignosulphonate as wetting agent in separation of PVC from PET/PVC mixture using froth flotation technique is studied in the present work. The conditions such as $\mathrm{pH}$ of wetting solution, separation time, composition and air velocity were optimized and results were compared with previously used calcium lignosulphonate as wetting agent. The re-usage of PVA showed consistent results, repeatedly for eight times, with high separation efficiency up to $80 \%$ and proved an economical substitute of calcium lignosulphonate as wetting agent in separation of PVC from PET/PVC mixture using froth flotation technique.
\end{abstract}

Key Words: Froth flotation, Wetting agent, Polyethylene terephthalate, Poly(vinyl alcohol), Poly(vinyl chloride).

\section{INTRODUCTION}

The production and applications of engineering polymers have increased considerably within last two decades due to their well-known properties including light weight, flexibility to use, low cost, high insulating properties, low degradability and high resistance to corrosion ${ }^{1}$. The annual growth rate of engineering polymers/plastics in the world is $7.5 \%$ and specifically in Asian countries, it is $15 \%$. The wide spread and escalating use of these polymers have created many environmental problems and require the development of novel management techniques to handle these waste polymers besides reduction of consumption, reuse, energy production and recycling. Although recycling is considered as one of the most feasible solution to cater the plastic waste but it is not implemented widely due to cost involved in the process. In developing countries like Pakistan, instead of recycling, it is dumped in land which is severely enhancing environmental problems due to non biodegradable nature of plastic materials ${ }^{2}$.

Although recycling process helps in minimizing waste disposal problems however, it requires separation and classi- fication of plastics prior to re-processing in order to maintain the quality of products made from recycled materials. The separation of polymeric materials is primarily dependent on the density difference and various techniques used in this regard such as air classification, sedimentation and elutriation. Other methods include repolymerization sorting based on LASER scanning of polymers and froth flotation. Some of the techniques used on industrial scale are manual sorting and gravity separation. Although, manual sorting is comparatively low cost process but it requires much time and labor. Moreover, gravity separation is effective if large density difference exists between the polymers to be separated (densities for common engineering polymers is given in Table- 1$)^{3-5}$.

TABLE-1

DENSITIES OF POLYMERS

\begin{tabular}{lc}
\multicolumn{1}{c}{ Polymer type } & Density $\left(\mathrm{g} / \mathrm{cm}^{3}\right)$ \\
\hline Polyethylene terephthalate (PET) & $1.330-1.390$ \\
Poly(vinyl chloride) (PVC) & $1.330-1.400$ \\
Polystyrene (PS) & 1.050 \\
Polyethylene (PE) & 0.960 \\
Polypropylene (PP) & 0.900 \\
\hline
\end{tabular}


Polyethylene terphthalate is most recycled product and can be efficiently separated from other polymeric materials like polypropylene, polystyrene and polyethylene but main problem is faced in the separation of PVC from PET due to their overlapping density range as given in Table-1. Separation of PVC is necessary from PET before recycling as its contamination results in its degradation to produce char which ultimately affects the quality and cost of recycled $\mathrm{PET}^{6}$.

Froth flotation is being practiced since many years to separate materials having close density range like PVC and PET. The simplicity of the process and the low operating cost could be the additional features of this process in which difference in surface wettability produced by the surfactant on selective plastic surface is taken as basis for separation ${ }^{7}$. Both the polymers PVC and PET are hydrophobic in nature but due to the presence of oxygen molecule, PET has a tendency to be hydrophilic in the presence of suitable wetting agent ${ }^{7-11}$.

In the present work, separation of PVC/PET mixture is studied with PVA as wetting agent using froth flotation technique. The effect of feed composition, $\mathrm{pH}$ of media, separation time and air velocity has also been studied for the various samples of PVC/PET mixture collected from industry to find the optimum conditions. Experimental results are also compared with calcium lignosulphonate (CaLs) to check feasibility of PVA as wetting agent in term of separation efficiency.

\section{EXPERIMENTAL}

The samples of PVC/PET mixture were obtained from a local industry where manual separation technique is being used for the separation of PVC from PET. The material was shredded, screened from 6 to 10 mesh, then cleaned using tap water and dried at room temperature. Both the materials (PVC/PET) were taken in different colours, (PET in green and PVC in transparent colour) to ease the calculation of separation efficiency at the end of the experiment. The chemicals used in this experiment were $\mathrm{NaOH}$ and $\mathrm{HCl}$ as $\mathrm{pH}$ regulator, calcium lignosulphonate and PVA as wetting agents whereas polyacrylamide and sodium dodecyl sulfate were used as frothing agent. All the chemicals were analytical reagent grade purchased from Sigma Chemical Co. (St. Louis, MO, USA). The $\mathrm{pH}$ was measured with $\mathrm{pH}$ meter model (WTW-720, Mettler Toledo, USA) and to evaluate the wet-ability of PVC/PET, contact angle measurement was made by sessile drop method using goniometer (model JYSP360, Beijing United Test Co.Ltd., China).

Pretreatment: The samples of polymeric materials (PVC/ PET) were treated with $1 \mathrm{M} \mathrm{NaOH}$ using a magnetic stirrer for $10 \mathrm{~min}$ in a glass beaker at room temperature to minimize the hydrophobicity of PET material ${ }^{12}$. The sample was then rinsed with tap water and dried at room temperature.

Polymer conditioning with wetting agent: After pretreatment, conditioning of sample polymeric material (PVC/ PET) was carried out in a column (39.4 inches in length and 36.6 inches in diameter) equipped with a stirrer for $0.5 \mathrm{~h}$ in the solution of calcium lignosulphonate $(400 \mathrm{mg} / \mathrm{L})$ and PVA $(400 \mathrm{mg} / \mathrm{L})$ to enhance the selective affinity of air bubbles for PVC flakes. Polyacrylamide $(3 \mathrm{~mL} / \mathrm{L})$ and sodium dodecyl sulfate $(1 \mathrm{mg} / \mathrm{L})$ were used as frothing agents.

The block diagram of PVC/PET separation process is shown in Fig. 1.

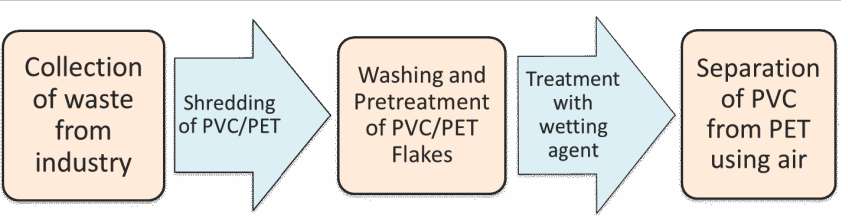

Fig. 1. Block diagram of PVC/PET separation process

\section{RESULTS AND DISCUSSION}

Effect of separation time on separation efficiency: The effect of change of separation time on the separation efficiency was studied under the identical operating conditions while keeping the composition of polymer mixture, conditioning time and $\mathrm{pH}$ of media constant. The effect of separation time on purity of PVC recovery by applying wetting agents (calcium lignosulphonate and PVA) revealed that with the increase in separation time, PVC recovery was increased but purity of recovered material was not enhanced considerably after $5 \mathrm{~min}$ (Fig. 2). Hence 5 min could be taken as optimum separation time for separation of PET/PVC mixture for both wetting agents (PVA and calcium lignosulphonate).

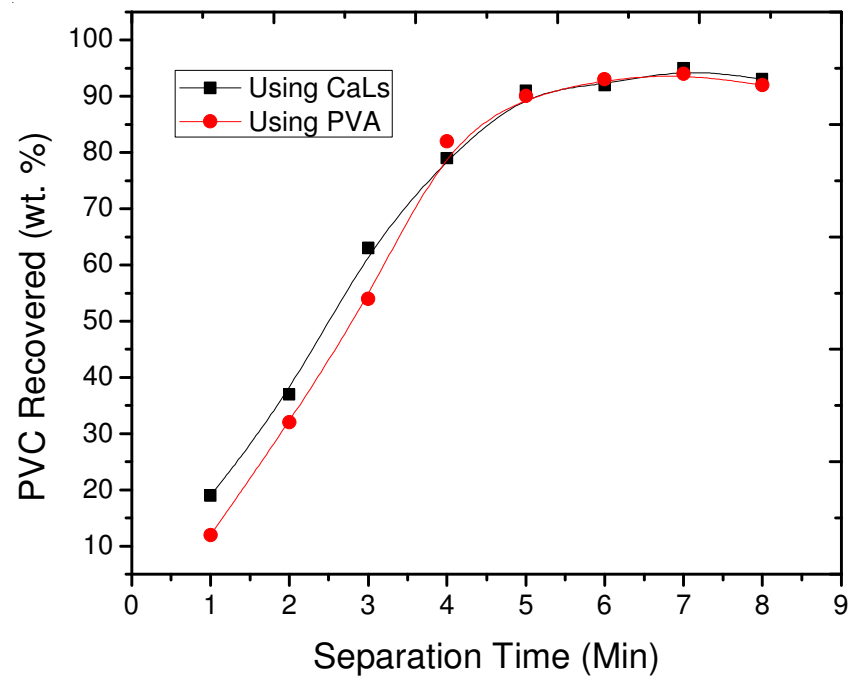

Fig. 2. Effect of separation time on purity of PVC recovery (at $\mathrm{pH} 11$ and air flow rate $80 \mathrm{scfh}$ )

Effect of air velocity: In second stage, effect of air velocity on separation phenomena by froth flotation technique was studied at optimum $\mathrm{pH} 11$, separation time $5 \mathrm{~min}$, conditioning time $0.5 \mathrm{~h}$ and composition of feed constant $(0.25 \mathrm{wt} \%$ on PVC basis), using both wetting agents under the same operating conditions. At low air velocity, separation results were poor because the froth was not able to carry PVC particles from the solution. Materials recovery was improved at high air flow rate as shown in Fig. 3.

However, at high air velocity, turbulence in the column decrease the purity of PVC recovered. This showed that due to high turbulence in the column, some PET particles were also captured in the froth and thus resulted in less purity of PVC recovered as shown in Fig. 3. Optimum results in term of PVC recovery and purity of recovered material were achieved for air flow of $80 \mathrm{scfh}$.

Effect of feed composition: Effect of change of feed composition on separation efficiency of polymer material (PVC/PET) 


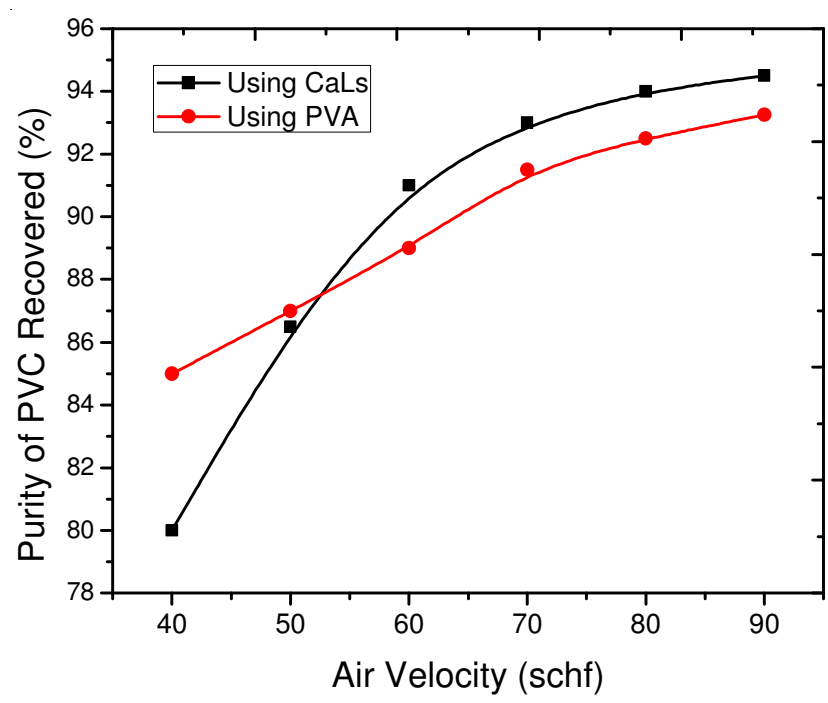

Fig. 3. Effect of air velocity on purity of PVC recovery

was also studied to determine the feasibility of separation process for low PVC contents in the feed as well. Fig. 4 shows that froth flotation technique can be successfully employed even for very low amount of PVC (only $0.25 \%$ ) in the feed.

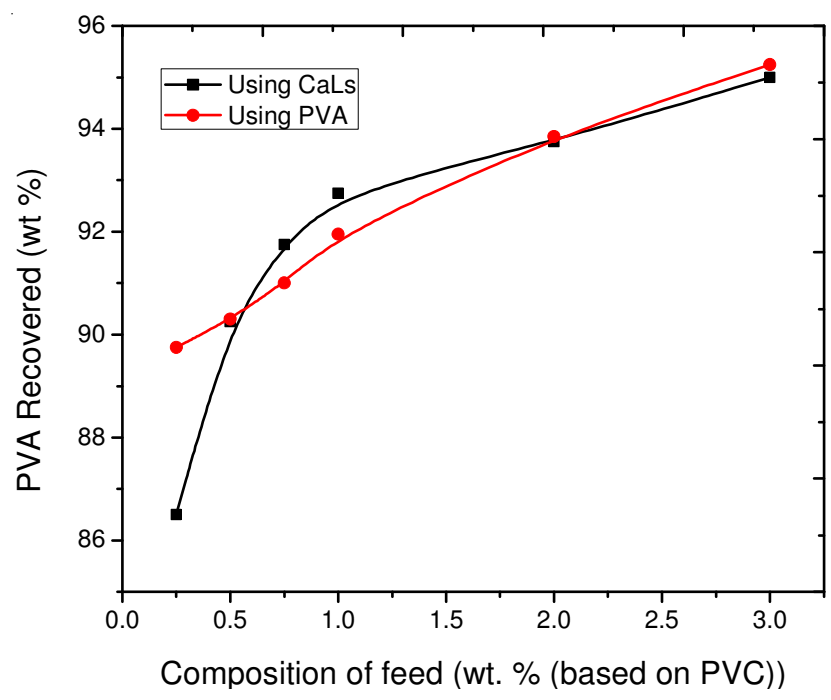

Fig. 4. Effect of feed composition on PVC recovery

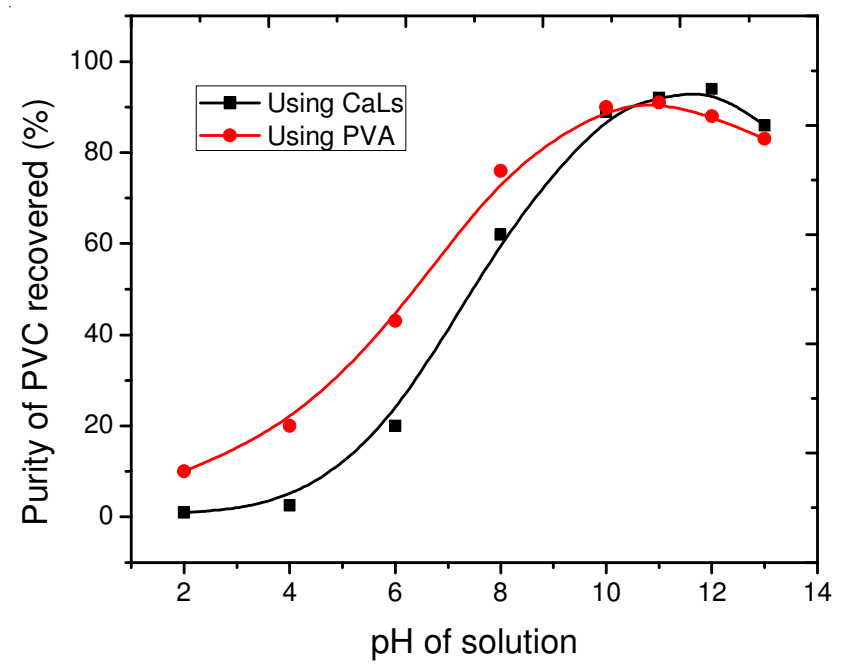

Fig. 5. Effect of pH on purity of PVC recovery (at air flow rate $80 \mathrm{scfh}$ )
Effect of $\mathbf{p H}$ on separation efficiency: To evaluate the effect of change of $\mathrm{pH}$ on the separation efficiency the experiments were performed for both the wetting agents calcium lignosulphonate and PVA, respectively under the same operating conditions keeping the conditioning time and separation time 30 and $5 \mathrm{~min}$, respectively.

Although some material was recovered at $\mathrm{pH} 2$ (acidic media), but purity of recovered PVC was very low with both calcium lignosulphonate and PVA which shows that hydrophobicity of both polymers keeps alive in the acidic media. As $\mathrm{pH}$ of the solution was further increased, surface properties of PET were altered and change in average contact angle was observed from ca. $83 \pm 3$ to $51 \pm 2^{\circ}$ (Fig. 6) which is an indication of the change from hydrophobic to hydrophilic nature at $\mathrm{pH} 11^{11}$. This change from hydrophobic to hydrophilic nature of PET can be attributed to the fact that when calcium lignosulphonate or PVA solution is adsorbed on PET by physisorption, the PET material acquires hydrophilic function, while calcium lignosulphonate and PVA are less adsorbed on PVC and its nature slightly changes. These results are in agreement to the previous studies reported by Drelich et al. ${ }^{6}$ and Abbasi et ll $^{11}$.

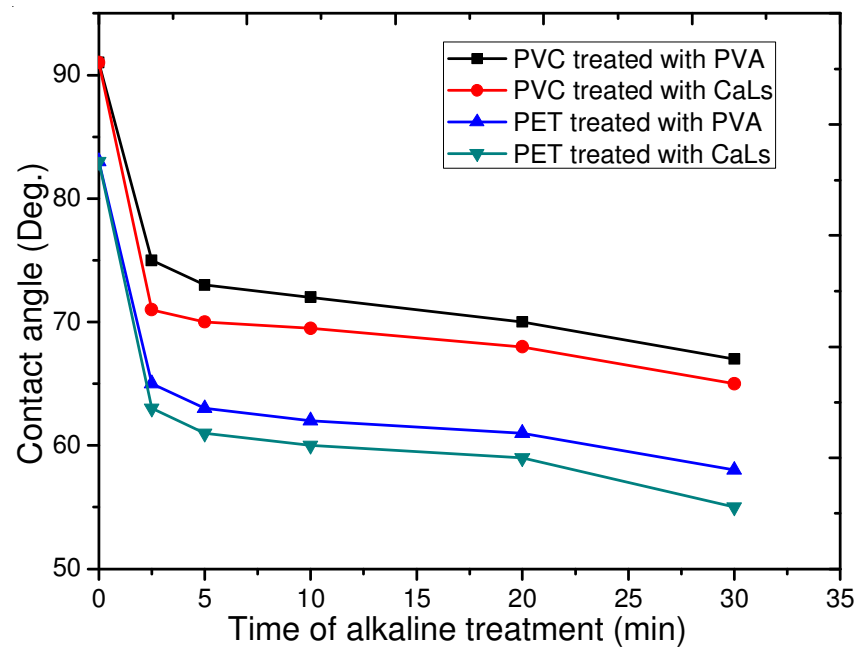

Fig. 6. Effect of PVA and calcium lignosulphonate on contact angle of PET and PVC

Furthermore, calcium lignosulphonate and PVA have shown significant results at $\mathrm{pH} 11$ as shown in Fig. 5, no remarkable increase in recovery efficiency was observed above $\mathrm{pH} 11$ in case of both the wetting agents. However, a declined effect was observed above $\mathrm{pH} 11$ especially at $\mathrm{pH} 13$ which shows that if alkalinity of media is increased, hydrophobicity of PVC may also be affected which suppresses down the separation results. Thus, $\mathrm{pH} 11$ could be taken as optimum in case of both the wetting agents.

Drelich et al. ${ }^{6}$ found that strong alkaline solutions of sodium hydroxide can tear down the hydrophobicity of PET material while for PVC, it is slightly changed by these solutions and on this basis, up to $95 \%$ recovery of PET can be achieved with the removal of most PVC from the $\mathrm{PET}^{6}$. Besides, the concentration, temperature and time of treatment are important to achieve a considerable difference in hydrophobicity between PVC and PET particles. 
Reuse of PVA: Effect of used PVA solution as wetting agent on separation efficiency for each run was also studied. Experiments were performed for $0.25 \mathrm{wt} \% \mathrm{PVC}$ in PVC/PET mixture at pH 11 using air at $80 \mathrm{scfh}$. Fresh PVA was not added, however, $\mathrm{pH}$ of solution was maintained at 11 for every run using $1 \mathrm{M} \mathrm{NaOH}$. The experimental data shows consistent results, repeatedly for eight times, with separation efficiency up to $80 \%$ as shown in Fig. 7. However, in the 9 th run efficiency was dropped below $80 \%$.

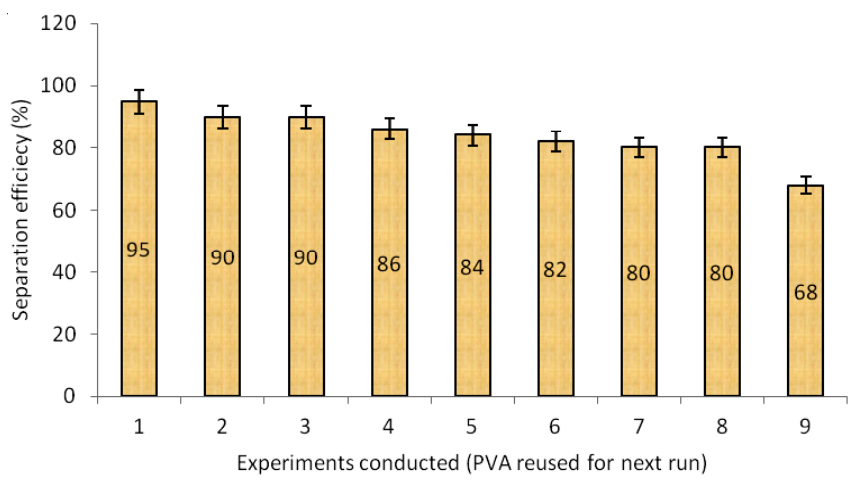

Fig. 7. Effect of reused PVA solution on separation efficiency (at pH 11 and air flow $80 \mathrm{scfh}$ )

\section{Conclusion}

The froth flotation tests were performed for the selective separation of PVC from PVC/PET mixture. Experiments showed that choice of wetting agent, $\mathrm{pH}$ of wetting media, composition of feed and air velocity are the major factors in the selective separation and purity of the recovered material. Two wetting agents, calcium lignosulphonate and PVA were used for PVC/PET mixture separation and a comparative study for both was conducted in the presence of sodium dodecyl and polyacrylamide that were used to stabilize froth to carry the PVC particles. Although, calcium lignosulphonate has been the focus of many researchers in froth flotation technique and gives better results, but, experimental results shows that PVA could also be used to selectively suppress the surface properties of PET with the comparable efficiency. Presence of $\mathrm{OH}$ group in PVA helps in temporarily changing the hydrophobic nature of PET to hydrophilic one. Also the market price of calcium lignosulphonate $(0.285 \$ \mathrm{~g}$ from Greatchem $)$ is more than that of PVA $(0.0276 \$ / g$ from Dupont]. This also makes PVA more feasible wetting agent compared to calcium lignosulphonate. The re-usage efficiency of PVA was also studied and found giving high separation efficiency for about 8 times. Thus PVA can be taken as an economical substitute of calcium lignosulphonate as wetting agent in separation of PVC from PET/PVC mixture using froth flotation technique.

\section{ACKNOWLEDGEMENTS}

The support and grant from The University of Punjab, Lahore, Pakistan to conduct this research work is gratefully acknowledged.

\section{REFERENCES}

1. F. Burat, A. Guney and M.O. Kangal, Waste Manage., 29, 1807 (2009).

2. S.A. Batool, C. Nawaz, K. Majeed, Waste Manage. Sci. Technol., 28, 294 (2008).

3. G.A. Serad and T.S. Thornburg, US Patent 5,462,973 (1995).

4. R. Dvorak and E. Kosier, In proceedings of ANTEC-2000 Conference, Society of Plastic Engineers, USA (2000).

5. T. Takoungsakdakun and S. Pongstabodee, Sep. Purif. Technol., 54, 248 (2007)

6. J. Drelich, J.H. Kim, T. Payne, J.D. Milleret and R.W. Kobler, Sep. Purif. Technol., 15, 9 (1999).

7. G.A. Marques and J.A.S. Tenorio, Waste Manage., 20, 265 (2000).

8. H. Shen, R.J. Pugh and E. Forssberg, Colloid. Surf. A, 196, 63 (2002).

9. S. Saisinchai, J. Metals Mater. Miner., 13, 79 (2004).

10. X. Ouyang, X. Qiu and P. Chen, Colloid. Surf A, 282, 489 (2006).

11. M. Abbasi, M.M. Salarirad and I. Ghasemi, Iran. Polym. J., 19, 483 (2010).

12. N. Fraunholcz, Miner. Eng., 17, 261 (2004). 